\title{
Characterization of $\mathrm{Nb}_{2} \mathrm{O}_{5}-\mathrm{Ni}$ Coating Prepared by DC Sputtering
}

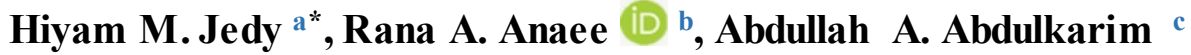 \\ a Material Engineering Department, University of Technology, Baghdad, Iraq, hoyamhimi123@gmail.com \\ b Material Engineering Department, University of Technology, Baghdad, \\ Iraq,130033@uotechnology.edu.iq \\ ${ }^{\mathrm{c}}$ Ministry of Industry and Minerals, Baghdad, Iraq masterchem76@yahoo.com \\ *Corresponding author.
}

Submitted: $29 / 10 / 2020$

Accepted: 07/12/2020

Published: $25 / 04 / 2021$

K E Y W O R D S

$\mathrm{Nb}_{2} \mathrm{O}_{5}$-Ni coating; $\mathrm{DC}$ sputtering; SEM, EDS, Microhardness,

\section{A B S T R A C T}

The $\mathrm{Nb}_{2} \mathrm{O}_{5}-\mathrm{Ni}$ coating was processed using DC sputtering on structural steel and study characterization of composite coating SEM/EDS inspection indicated clearly perfect incorporation of $\mathrm{Nb}_{2} \mathrm{O}_{5}$ within the nickel rich. Increasing in surface roughness and decreasing in average diameters of particles were obtained for coated surface compared with uncoated surface from AFM analysis, in addition, microhardness test and thickness test showed that increasing of the hardness value to $163 \mathrm{HV}$ for $\mathrm{Nb}_{2} \mathrm{O}_{5}-\mathrm{Ni}$ composite coating compared to $132 \mathrm{HV}$ for uncoated samples, the hardness for Ni coating also increasing to $155 \mathrm{HV}$ and the thickness for $\mathrm{Nb}_{2} \mathrm{O}_{5}-\mathrm{Ni}$ composite coatings increased significantly compared to uncoated samples.

\footnotetext{
How to cite this article:H. M. Jedy, R. A. Anee, and A. A. Abdulkarem, "Characterization of $\mathrm{Nb}_{2} \mathrm{O}_{5}$-Ni Coating Prepared by DC Sputtering", Engineering and Technology Journal, Vol. 39, Part A, No. 04, pp. 565-572, 2021.

DOI: https://doi.org/10.30684/etj.v39i4A.1902

This is an open access article under the CC BY 4.0 license http://creativecommons.org/licenses/by/4.0
}

\section{INTRODUCTION}

Coating processes give protection to structure surfaces that exposed to aggressive and corrosion environments in various fields, so considered necessary for some applications [1]. Thin-film or coating is called a new field of chemistry/materials. The structure of thin-films, like all material, is divided into amorphous and polycrystalline structures, depending on the condition of preparation and the material composition. Thin-film consists of two parts: the substrate and the substratum on which the film is mounted [2]. Glow discharges and associated plasma are used in a large number of application fields. When a sample is exposed to the plasma, ionized atoms and molecules may react with the surface exposed. Various effects are commonly observed, including etching, sputtering and material surface alteration $[3,4]$. 
The plasma is generated in a plasma reactor DC glow discharge by supplying a potential DC between two electrodes. The electrodes are in a jar that was evacuated. The vacuum is applied in a plasma forming medium. Natural processes initially ionized a small group of atoms containing the cell. The interaction of a cosmic ray or photon with a molecule or plasma gas atom releases an electron. This will a plasma reactor for ion DC glow discharge; the plasma is created by supplying the potential DC from two electrodes.

Sputtering deposition theory predicts that sputtering caused by the formation of very high local temperatures by bombarding ions, which contributes to the evaporation of target material from those local areas. [5] Sputtering also is a method of ejecting atoms from the solid surface through the action of energetic particles [5]. To protect steel surface there are many methods used of metallic coatings such as $\mathrm{Ni}, \mathrm{Zn}, \mathrm{Cu}$ and alloy coating such as $\mathrm{Zn}-\mathrm{Ni}$, Ni-Co, etc. The inclusion of nano or micro-sized particles in the coating has been found to enhance steel corrosion resistance. Such coating was known as composite coating and view higher resistance of corrosion to increase hardness [6].

Niobium oxide has been suggested as a suitable replacement for $\mathrm{Ta}_{2} \mathrm{O}_{5}$ in solid electrolyte $\left(\mathrm{Ta}_{2} \mathrm{O}_{5}\right)$ condensers, where the dielectric oxide layer is produced from porous metal compressed from anodic oxidation. Due to the larger permittivity of $\mathrm{Nb}_{2} \mathrm{O}_{5}$ compared to $\mathrm{Ta}_{2} \mathrm{O}_{5}$, it is a suitable replacement due to its similar anodization nature and provides the benefit of greater natural abundance. With a wide variety of technical applications such as sensing materials to assist catalytic processes, niobium oxide films were proposed. The coatings are biocompatible due to the good chemical stability and resistance to corrosion for both acid and base media. [7]. $\mathrm{Nb}_{2} \mathrm{O}_{5}$ films were prepared using various methods, including magnetron sputtering, electrodeposition, anodization, thermal oxidation, sol-gel processes, chemical vapor deposition (CVD) and epitaxy of the atomic layer [8]. $\mathrm{Nb}_{2} \mathrm{O}_{5}$ is present in different polymorphic shapes; $\mathrm{TT}-\mathrm{Nb}_{2} \mathrm{O}_{5}$ (pseudo-hexagonal), $\mathrm{T}-\mathrm{Nb}_{2} \mathrm{O}_{5}$ (orthorhombic) and $\mathrm{H}-\mathrm{Nb}_{2} \mathrm{O}_{5}$ (monoclinic) are the most common phases. The most thermodynamically stable form is the H-phase, while the least stable is the TT-phase. It is reasonably easy to transform the TT-phase to the H-phase of sufficient heat treatment. Similarly, at a lower temperature, the amorphous niobium acid can be converted into TT- $\mathrm{Nb}_{2} \mathrm{O}_{5}$. At $600-800$ oC, by

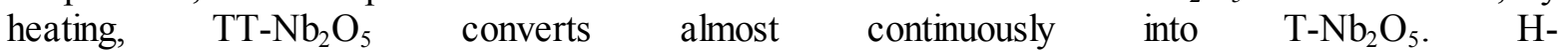
$\mathrm{Nb}_{2} \mathrm{O}_{5}$ originates from all other air heating forms at roughly $1100{ }^{\circ} \mathrm{C}$ [9]. To achieve good corrosion resistance, the steel chemistry and processing technique need to carefully construct. $\mathrm{Nb}_{2} \mathrm{O}_{5}$ is believed to show capable of increasing steel strength with no great loss in ductility and durability and improving specific corrosion resistance [10]. In this work, $\mathrm{Nb}_{2} \mathrm{O}_{5}-\mathrm{Ni}$ coating was deposited by DC sputtering on carbon steel to investigate the corrosion resistance in seawater at 303 and $333 \mathrm{~K}$ and analysis the characterization of the composite coating.

Reviews of literature provide some researches, which is done in this field, it's:

Yinsong et al. In (2003), prepared $\mathrm{Nb}_{2} \mathrm{O}_{5}$ films by DC reactive sputtering process. These structural features include solid electrochemical stability, high reversibility of $\mathrm{Li}^{+}$injection/extraction and better Electrochromic property. The colorless blank and brownish-gray color of DC sputtered $\mathrm{Nb} 2 \mathrm{O} 5$ films may be a promising candidate for electro chrome applications [11].

Nilgiin et al. In (1996), prepared Electrochromic niobium coatings by the sol-gel spin-coating and DC magnetron sputtering techniques. XRD analysis shows the sol-gel process and magnetron sputtering films for temperatures below $450{ }^{\circ} \mathrm{C}$.was amorphous. However, the structure was crystalline at a temperature higher than $450{ }^{\circ} \mathrm{C}$. X-ray photoelectron spectroscopy (XPS) Studies indicated that $\mathrm{Nb}_{2} \mathrm{O}_{5}$ stoichiometry of films. The electrochemical activity or structural changes in 1 $\mathrm{M} \mathrm{LiClO}_{4} /$ propylene carbonate solution was observed [12].

H. Chen et al. (2015), applied electroless plating to deposit ternary Ni-P-W coatings forming dispersed $\mathrm{Nb} 2 \mathrm{O} 5$ particles mostly on sintered $\mathrm{NdFeB}$ substrates. During electroless plating, the influence of experimental process conditions was investigated on the deposition rate. Experimental research tested the performance of coatings, like corrosion resistance, interlayer adhesion strength and micro-hardness [13].

M.F. Pillis et al. in (2016), applied niobium oxide thin-films to stainless steel substrates AISI 316 by sputtering the reactive DC magnetron. Niobium oxide films have been studied in their structure, 
composition, and corrosion resistance. Electrochemical impedance spectroscopy (EIS) and potentiodynamic polarization evaluated the corrosion behavior of the specimens. X-ray diffractometry analyzed the structure of the film. The $\mathrm{Nb}_{2} \mathrm{O}_{5}$ layers increased the corrosion resistance of the substratum. The best performance in protection was achieved at $15 \mathrm{~min}$ deposition time [14].

R. M. Reddy et al. in (2017) prepared the $\mathrm{Ni}-\mathrm{Nb}_{2} \mathrm{O}_{5}$ composites by the pulse electrodeposition method. Optimization study was achieved to obtain a uniform deposition layer. X-ray diffraction (XRD) and scanning electron microscopy (SEM) were used to study both coating's structure and surface morphology. The coefficient of texture and hardness of the deposits was determined. Traditional weight loss and electrochemical approaches were used to analyze the coating's corrosion behavior. Comparisons of the corrosion behavior of straight current (DC) and pulse current (PC) coatings have been investigated [15].

\section{EXPERIMENTAL}

\section{Sample Preparations}

Steel (AISI 1015) specimens prepared to study the electrochemical test. Firstly, cutting the specimen is considered an important parameter in corrosion resistance and a uniform surface has to be prepared. Square specimens cut of the electric saw $(2 \mathrm{~cm} \times 2 \mathrm{~cm} \times 1 \mathrm{~cm})$ and then collected as a final. Specimen. shape. Secondly, grinding and polishing the specimen's accomplished, though, series of 400, 600, 800 and 1000 silic on carbide papers to achieve smooth, scratch-free surface and show the chemical composition test for carbon steel samples in TABLE 1.

TABLE I: Chemical composition of carbon steel.

\begin{tabular}{lccccl}
\hline \hline Element & $\mathbf{C}$ & $\mathbf{S i}$ & $\mathbf{M n}$ & $\mathbf{P}$ & $\mathbf{S}$ \\
\hline Wt.\% & 0.161 & 0.271 & 0.425 & 0.0073 & 0.0049 \\
\hline Standard & $\mathrm{C}$ & $\mathrm{Si}$ & $\mathrm{Mn}$ & $\mathrm{P}$ & $\mathrm{S}$ \\
\hline Wt.\% & $0.13-0.18$ & 0.29 & $0.30-0.60$ & 0.040 & 0.050 \\
\hline
\end{tabular}

\section{Preparation of Target coating and technique}

Powders of nickel and niobium pentoxide have been used during this work. Powders were used in the coating were both $\mathrm{Ni}$ and Niobium pentoxide. X-ray diffraction (XRD) test performed to verify the powders showed in Figure 1. Also, the preparation of the powders achieved by mixing and pressed by a pneumatic specimen punch device. The load was 8 bars for $1 \mathrm{~min}$. which are used during press with the steps, as shown in Figure 2.
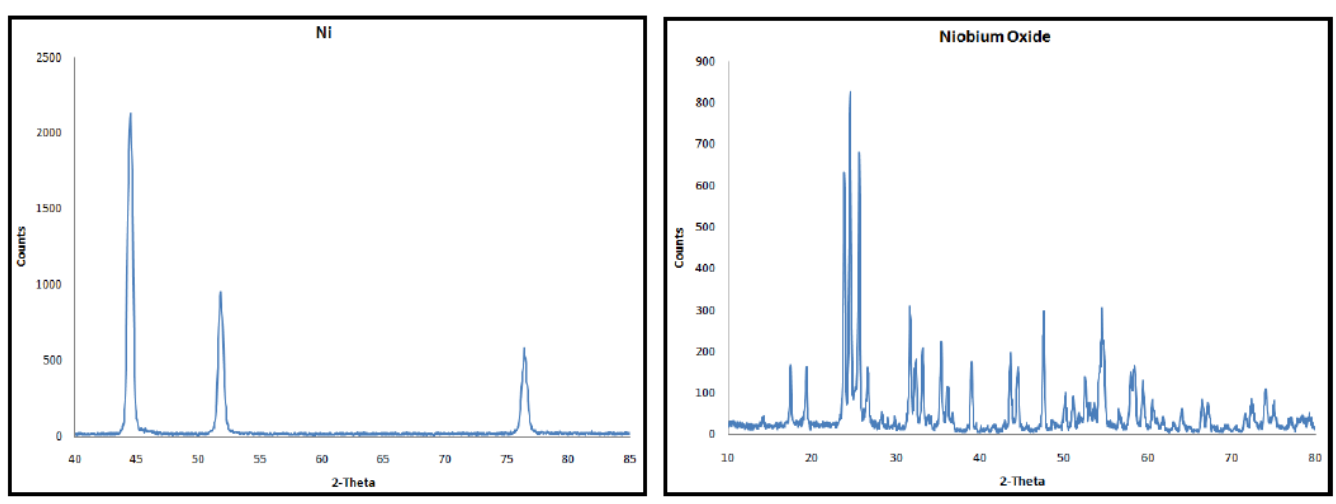

Figure 1: XRD of a pattern of $\mathrm{Ni}$ powder and $\mathrm{Nb2O5}$ powder. 


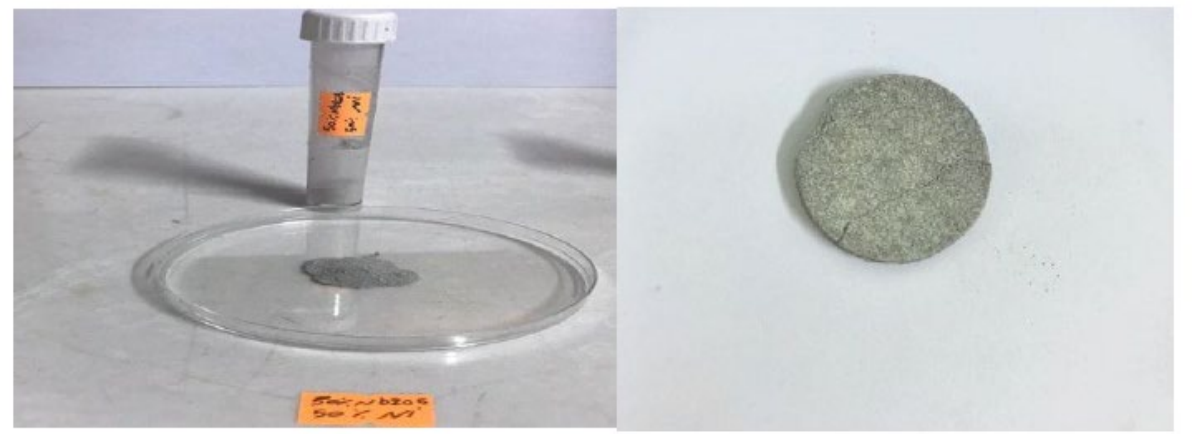

Figure 2: Preparation of Target coating.

DC sputtering technique was consisted of the target (cathode) and anode disk of stainless steel. The cathode opposite the anode and provides the gas discharge with the electrical field. The plasma chamber consisted of electrical electrodes and a $4 \mathrm{KV}$ DC power supply connected with them. The cathode electrode's bottom change is protected by an insulator disk (ceramic) and quartz tube with a diameter of $14.5 \mathrm{~cm}$ while the target electrode with an area of $7.5 \mathrm{~cm}$ and the distance between them is $3.5 \mathrm{~cm}$. The gas source-flow controller system is responsible for supplying the feedstock at the desired flow rate and gas pressure to the plasma chamber. It is consisting of dual-stage regulators, tubing and fittings for the gas storage cylinders (Argon). The dual-stage needle valve regulated the flow pressure to the plasma chamber. This system consists of a turbopump (Variant.V-1000HT) assisted by a hydraulic rotary pump $(60 \mathrm{~m} 3 / \mathrm{h}$. Balzer). The installation of penning (Edward CP25-K with controller 1102) and Perani gauges (LH-Thermovac with Combitron CM350) in the plasma chamber was required to monitor the actual pressure and the partial pressure of the discharge gases.

\section{CHARACTERIZATION METHODS}

Using the scanning electron microscope (SEM) and its calibrated energy dispersive spectrometer (EDS), the morphologies and chemical compositions of the obtained coating were studied and this test was carried out at the University of Sanity Sheriff Tehran-Iran. The coating roughness was assessed at the College of Science at the University of Baghdad using an AFM (Model AA3000 Scanning Probe Microscope) image analysis.

\section{ANALYSES AND Discussion}

\section{Characterization of $\mathrm{Nb2O5-Ni} \mathrm{coating}$}

SEM/EDS inspection was performed for coated surfaces to confirm the presence of $\mathrm{Nb}_{2} \mathrm{O}_{5}-\mathrm{Ni}$ composite as a coating. Figure 3 shows the typical very small nodular structure. The nodules were uniformly and densely distributed, but pores were still present in the coating. This figure exhibited the deposition of $\mathrm{Ni}$ film on carbon steel, while the SEM of $\mathrm{Nb}_{2} \mathrm{O}_{5}$-Ni coating that deposited by DC sputtering on carbon steel at the size of $200 \mathrm{~nm}$. The growth of crystallite nodules is seen as deposits that are dispersed on the surface of the steel. This obviously indicates a great integration of $\mathrm{Nb}_{2} \mathrm{O}_{5}$ within the rich nickel. Also, it can be notified that there are two characteristic phases showed within the interface, the first is nodular like solid flakes and the second phase is like homogeneous clusters at the background as also observed by Oluyori and co-workers when they deposited $\mathrm{Zn}-\mathrm{Nb}_{2} \mathrm{O}_{5}$ coatings by electrodeposition technique on mild steel [16]. Ni coating showed some of the agglomerations of particles be caused Ni coatings seem to be denser and compact in comparison with $\mathrm{Nb}_{2} \mathrm{O}_{5}$-Ni coatings due to faster deposition rate of DC sputtering as also observed by Jahanzeb Bhatti and co-workers when they Investigation of the mechanical properties of electrodeposited nickel and magnetron sputtered chromium nitride coatings deposited on mild steel substrate [17].

EDS analysis of Ni coated carbon steel shows $77 \mathrm{wt} \% \mathrm{Ni}$ and $23 \mathrm{wt} \% \mathrm{O}$ confirms the deposition of nickel and the oxygen content is due to oxidizing of some nickel. EDS of $\mathrm{Nb}_{2} \mathrm{O}_{5}$ - $\mathrm{Ni}$ coating illustrates the presence of $\mathrm{Nb}$ content as $38.1 \mathrm{wt} \%$, The presence of both nickel and oxygen in EDS of composite coatings was attributed to both oxidation and niobium oxide. 
(a)
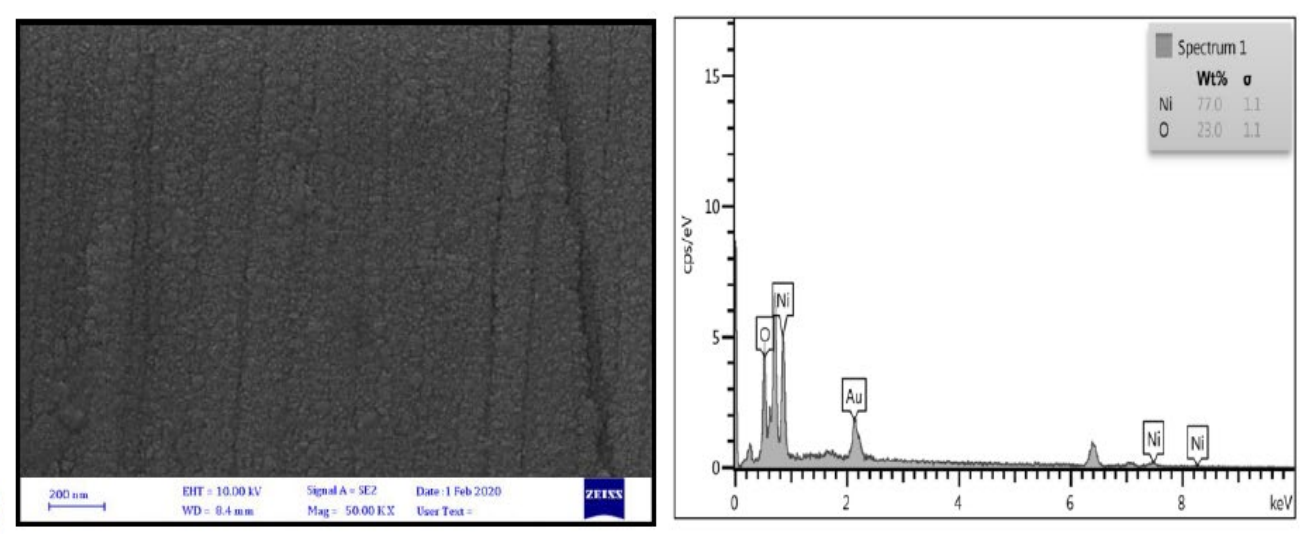

(b)
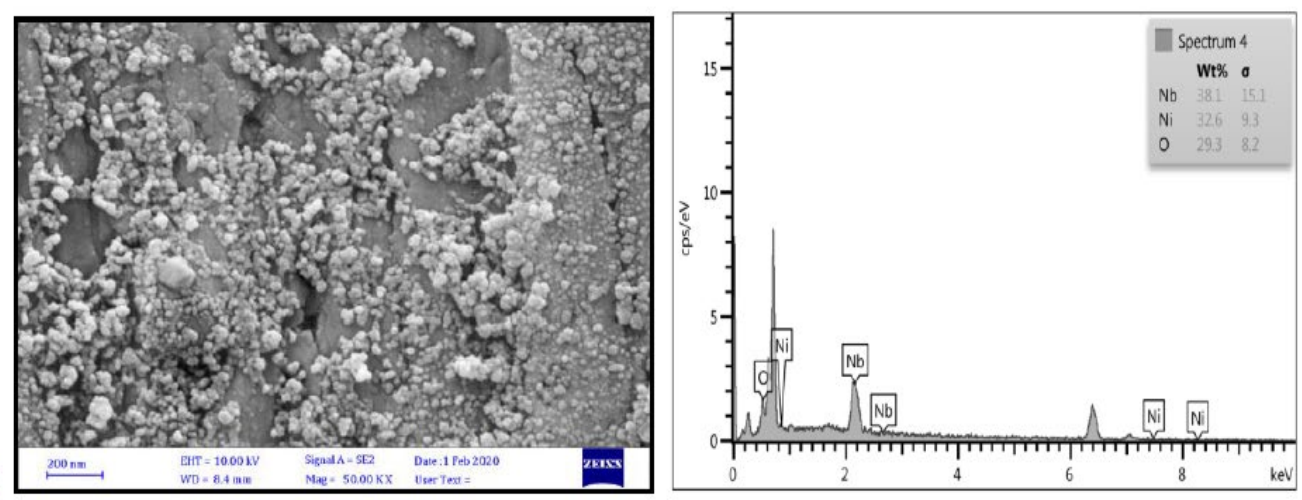

Figure 3: SEM/EDS of coated (a) Ni coated (b) Nb2O5-Ni coated.

AFM facilitates surface topography study, including measures of surface roughness. Additionally, because of the rough film shape and size, AFM records topographical images. Therefore, AFM images and force vs. distance graphs are therefore used to provide additional knowledge about surface film properties. Figure 4 illustrated the 2D and 3D images of uncoated and coated steel. Smooth surface can be shown on the uncoated steel surface with very little roughness equal to $(3.1 \mathrm{~nm})$. As shown in the TABEL 2. This result could be attributed to atmospheric corrosion and further confirmed by a random distribution of particles as shown in Figure 4 with a very high average diameter of $(148.05 \mathrm{~nm})$. For Ni coated surface, this result was a few summits and valleys on the surface that attributed to deposition of Ni particles. In addition to oxidizing some nickel to nickel oxide that gave a roughness average $(9.52 \mathrm{~nm})$ with uniform distribution of particle Figure 4. The average diameters equal to (81.13nm). Coating with Nb2O5-Ni composites gave a smoother surface compared with Ni coated samples and smoothness increases at increasing weight percent for $\mathrm{Nb} 2 \mathrm{O} 5$ to the composite as indicated from average roughness was obtained values that listed in TABEL 2. However more average diameter than Ni coating. A decrease in surface roughness is attributed to the $\mathrm{Nb2O5}$-incorporated $\mathrm{Ni}$ film resulting in the enhancement of grain growth to achieve a large particle size. 

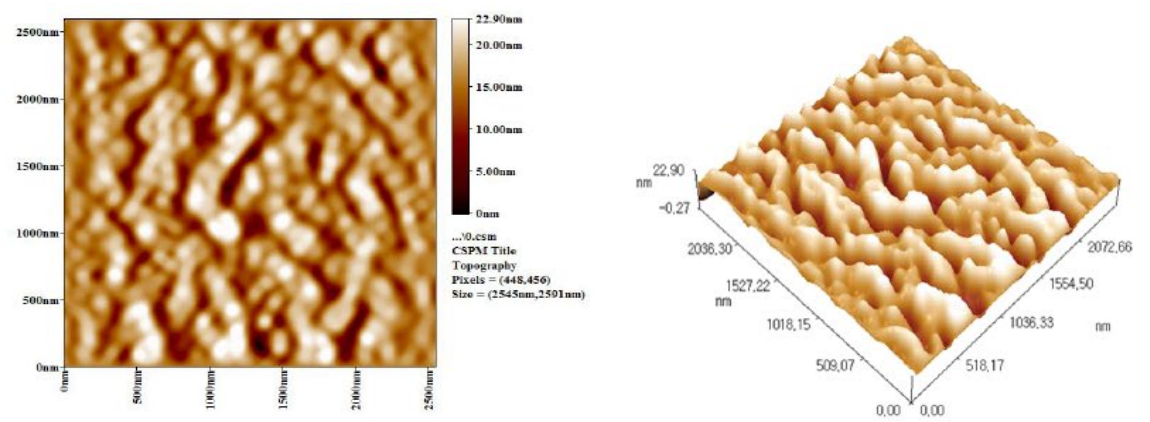

(a)

(b)
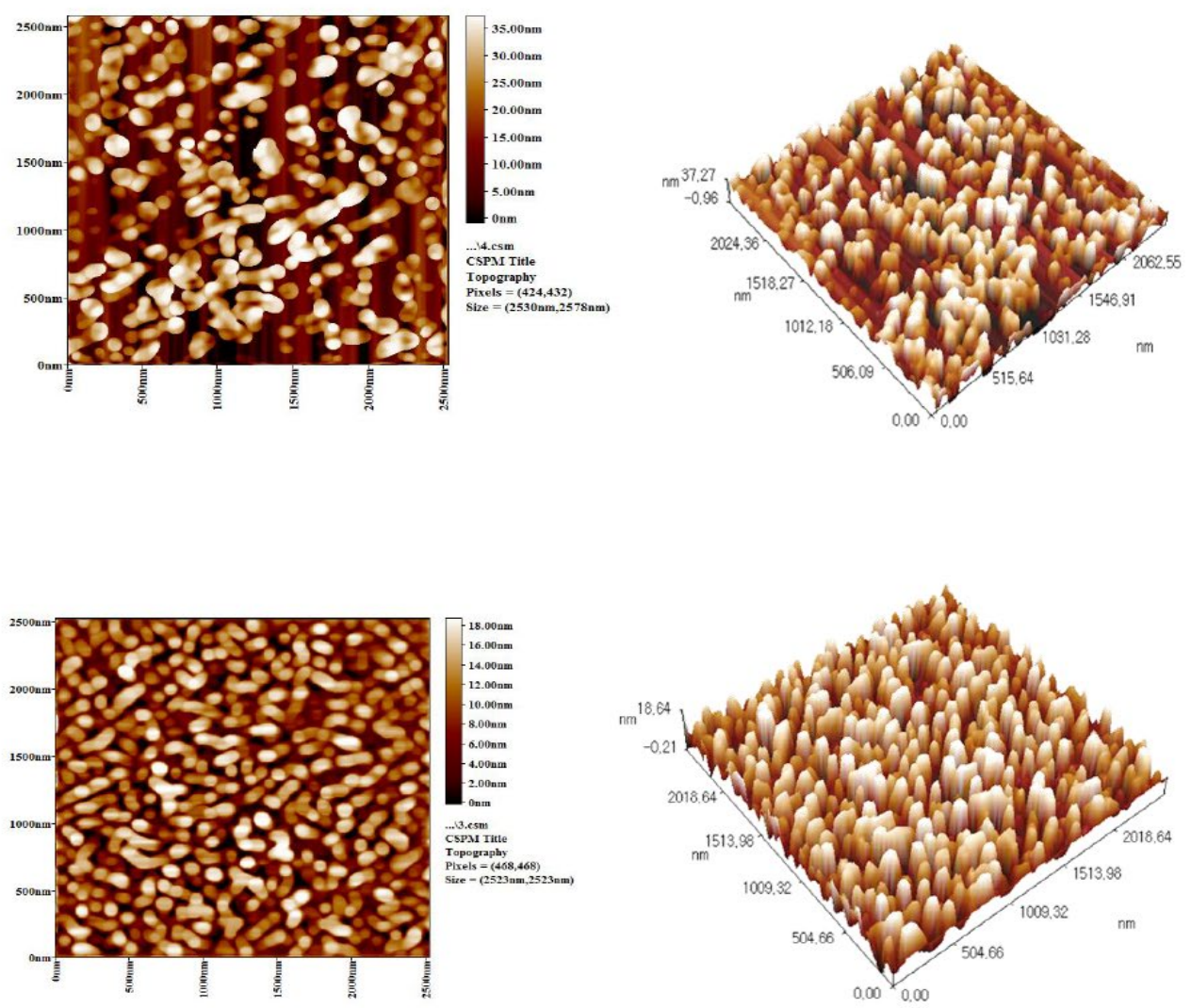

(c)

Figure 4: AFM images for (a) uncoated, (b) Ni coated (c) and $\mathrm{Nb}_{2} \mathrm{O}_{5}-\mathrm{Ni}$ coated.

TABLE II: AFM data in uncoated and coated samples.

\begin{tabular}{ccc}
\hline \hline Material coating & Roughness average (nm) & Average diameter (nm) \\
\hline Uncoated steel sample & 3.01 & 148.05 \\
\hline Ni coating sample & 9.52 & 81.13 \\
\hline $\mathbf{N b}_{2} \mathbf{O}_{5}$-Ni coated sample & 4.53 & 74.44 \\
\hline
\end{tabular}

\section{Microhardness and Thickness Test}

The microhardness test was done on coated specimens and results are listed in TABLE 3. The data shows the higher hardness of the surface Ni coated $(155 \mathrm{HV})$ compared with the uncoated surface $(133 \mathrm{HV})$. While increasing the hardness value of $\mathrm{Nb}_{2} \mathrm{O}_{5}$-Ni composite coating to $164 \mathrm{HV}$ compared with a hardness value of $\mathrm{Ni}$ coating surface. The incorporation of $\mathrm{Nb}_{2} \mathrm{O}_{5}$ with $\mathrm{Ni}$ coating 
led to the getting small increase to thickness coating by $\approx 6 \mu \mathrm{m}$ as shown in TABLE 3 because of filling any space between $\mathrm{Ni}$ particles by $\mathrm{Nb}_{2} \mathrm{O}_{5}$ particles.

TABLE III: $\quad$ Microhardness and thickness.

\begin{tabular}{lcc}
\hline \hline \multicolumn{1}{c}{ Coating type } & Microhardness $(\mathrm{HV})$ & Thickness $(\boldsymbol{\mu m})$ \\
\hline Uncoated steel sample & 133 & -- \\
\hline Ni coating sample & 155 & 5 \\
\hline $\mathrm{Nb}_{2} \mathbf{O}_{5}-\mathrm{Ni}$ coated sample & 164 & 6.4 \\
\hline
\end{tabular}

\section{CONCLUSIONS}

1) $\mathrm{Ni}$ and $\mathrm{Nb}_{2} \mathrm{O}_{5}$ - $\mathrm{Ni}$ composite coatings were deposited by DC sputtering to get uniformly and densely distributed thin-film with some pores that characterized by SEM/ EDS analysis and AFM examination.

2) Microhardness results showed an improvement in hardness value after DC sputtering.

3) Deposition other materials with nickel such as $\mathrm{TiO}_{2}-\mathrm{Ni}$, $\mathrm{ZnO}-\mathrm{Ni}$ and $\mathrm{Al}_{2} \mathrm{O}_{3}-\mathrm{Ni}$ composite coatings.

4) Deposition of $\mathrm{Nb}_{2} \mathrm{O}_{5}$ - $\mathrm{Ni}$ coatings with other techniques such as electrophoretic deposition, thermal spraying and RF sputtering.

\section{References}

[1] Y. Qian, Y. Li, T. Scott, N. Seely, Y. Fang, The Application of Anti-Corrosion Coating for Preserving the Value of Equipment Asset in Chloride-Laden Environments: A Review, Int. J. Electrochem. Sci., 10 (2015) $10756-10780$

[2] A. Jilani, M.Abdel-wahab, A.H.Hammad, Advance deposition techniques for thin-film and coating, Modern. Technol. Creat. Thin-film. Sys. Coat., 8 (2017)137-149. http://dx.doi.org/10.5772/65702

[3] F. F. Chen, Introduction to plasma physics and controlled fusion, Plenum Press, 2nd edition, New York. 1 (1985). https://doi.org/10.1007/978-3-319-22309-4

[4] M. A. Liebermann, A. J. Lichtenberg, Principles of Plasma Discharges and Materials Processing, 2nd Edition, (2005) 800 .

[5] M. K. Khammass, Investigation of the interaction of glow discharge plasma with metal surfaces, Ph.D. Thesis, College of Science, University of Baghdad, Iraq, 2010.

[6] C. M. P.Kumar, T.V. Venkatesha, R. Shabadi, Preparation and corrosion behavior of Ni and Ni-graphene composite coatings, Mater. Res. Bull., 48 (2013) 1477-1483 https://doi.org/10.1016/j.materresbull.2012.12.064

[7] G. Ramírez, S. E. Rodil, S. Muhl, D. Turcio-Ortega, J. J. Olaya, M. Rivera, E. Camps , L. Escobar-Alarcón, Amorphous niobium oxide thin-films, J. Non. Cryst. Solids., 356 (2010) 2714-2721 https://doi.org/10.1016/j.jnoncrysol.2010.09.073

[8] R. Fiz, L. Appel, A. Gutiérrez-Pardo, J. Ramírez-Rico , S. Mathur, Electrochemical energy storage applications of CVD grown niobium oxide thin-films, ACS. Appl. Mater. Interfaces., 8 (2016) 21423-21430. https://doi.org/10.1021/acsami.6b03945

[9] Y. Zhao, X. Zhou, L. Ye , S. C. E. Tsang, Nanostructured Nb2O5 catalysts, Nano Rev., 3 (2012) 17631. https://doi.org/10.3402/nano.v3i0.17631

[10] F. B. Destro, M. Cilense, M. P. Nascimento, F. G. Garcia, L. R. O. Hein, A. Z. Simões, Corrosion behaviour of Polycrystalline Nb2O5 thin-films and its size effects, Prot. Met. Phys. Chem. Surf., 52 (2016) 104-110. https://doi.org/10.1134/S2070205116010081

[11] Y. Huang, Y. Zhang, X. Hu, Structural morphological and electrochromic properties of Nb2O5 films deposited by reactive sputtering, Sol. Energy. Mater. Sol. Cells., 77 (2003) 155-162. https://doi.org/10.1016/S0927-0248(02)00318-5 
[12] N. Ozer, M. D. Rubin, C. M. Lampert, Optical and electrochemical characteristics of niobium oxide films prepared by sol-gel process and magnetron sputtering A comparison, Sol. Energy. Mater. Sol., 40 (1996) 285-296. https://doi.org/10.1016/0927-0248(95)00147-6

[13] H. Chen, Q. Wang, H. Dong, L.Xi, X. Lin, F. Pan , Z. Ma, Electroless plating of Ni-P-W coatings containing scattered $\mathrm{Nb} 2 \mathrm{O} 5$ on sintered NdFeB substrate, Mater. Res., 18 (2015) 1089-1096. https://doi.org/10.1590/1516-1439.032015

[14] M. F. Pillis, G. Uilherme, A.Geribola, G. Scheidt, E. G. de Araújo, M. Cristina Lopes de Oliveira, R. A. Antunes, Corrosion of thin, magnetron sputtered Nb2O5 films, Corros. Sci., 102 (2016) 317-325. https://doi.org/10.1016/j.corsci.2015.10.023

[15] R. M. Reddy, B. M. Praveen, C. M. P. Kumar, Corrosion behavior and characterization of Ni- Nb2O5 composites prepared by pulse electro deposition, Surf. Engin. Appl. Electrochem., 53 (2017) 179-185. https://doi.org/10.3103/S1068375517020090

[16] T. Oluyori, O. E. Olorunniwo, O. S. I. Fayomi, P. O. Atanda , A. P. I. Popola, Performance evaluation effect of $\mathrm{Nb} 2 \mathrm{O} 5$ particulate on the microstructural, wear and anti-corrosion resistance of $\mathrm{Zn}-\mathrm{Nb} 2 \mathrm{O} 5$ coatings on mild steel for marine application, J. Bio. Tribo. Corros., 3 (2017) 2-6. https://doi.org/10.1007/s40735-017-0108-x

[17] J. Bhatti, M. A. Fazal, A. Khan, A. R. Bushroa, M. M. Quazi, Investigation of the mechanical properties of electrodeposited nickel and magnetron sputtered chromium nitride coatings deposited on mild steel substrate, J. Adhes. Sci. Technol., 30 (2016) 2224-2235. https://doi.org/10.1080/01694243.2016.1178027 